\title{
Study on Effect of Number of Transparent Covers and Refractive Index on Performance of Solar Water Heater
}

\author{
B. Kalidasan ${ }^{1}$ and T. Srinivas ${ }^{2}$ \\ ${ }^{1}$ Energy \& Environmental Engineering, School of Mechanical and Building Science, VIT University, Vellore 632014, India \\ ${ }^{2} \mathrm{CO}_{2}$ Research \& Green Technologies Centre, School of Mechanical and Building Science, VIT University, Vellore 63201, India \\ Correspondence should be addressed to B. Kalidasan; kalidasancinna@gmail.com
}

Received 2 May 2014; Revised 26 July 2014; Accepted 2 August 2014; Published 1 September 2014

Academic Editor: Jing Shi

Copyright (C) 2014 B. Kalidasan and T. Srinivas. This is an open access article distributed under the Creative Commons Attribution License, which permits unrestricted use, distribution, and reproduction in any medium, provided the original work is properly cited.

Liquid flat plate collector (solar flat plate collector) is one of the important applications in solar thermal system. The development in solar photovoltaic is an emerging challenge for the solar thermal system. In the current work an attempt has been made to optimize the number of transparent covers and refractive index to improve the optical efficiency and thermal efficiency for the collector. Performance of the liquid flat plate collector at VIT University Vellore has been simulated numerically for January $21 s t$ at an interval of half an hour with different numbers of transparent covers (0-3) and different refractive index values ranging from 1.1 to 1.7. The formulation and solutions are developed with simple software Microsoft Office Excel to result the performance characteristics. The result shows that the efficiency of the flat plate collector increases with an increase in number of covers and decreases after an optimum number of covers. It also decreases with an increase in refractive index. The combination of optimum number (two) and lower refractive index (1.1) results improved useful heat.

\section{Introduction}

The selection of number of transparent covers and refractive index of transparent cover, in a liquid flat plate collector, will affect the performance of the flat plate collector, thus it's important in finding an optimum number of cover and an effective refractive index, for achieving higher efficiency irrespective of solar insulation and location. The flat plate collector is the heart of all solar energy thermal system designed for working at low temperature range of ambient to $60^{\circ} \mathrm{C}$. The flat plate collector is basically a heat exchanger which transfers the radiant energy of the incident sunlight to the sensible heat of a working fluid-liquid or air. The solar liquid flat plate collector for water heating was invented by Saussure [1], a Swiss scientist, during 1767, as reported by Ackermann in the year 1915. However the use of flat plate collector became more popular in 1900s at United States and at California. During the past fifty years researchers and scientist from all over the world have done many contribution in this field, in building and testing different types of liquid flat plate collector. Among these works, the literature in number of transparent covers and has been reviewed on contributions in refractive index and transparent cover's properties.

Lampert [2] discussed in detail the properties of optical materials and coatings, which would predominantly increase the performance of the solar thermal system. He highlighted that for reducing the radiative loss between the top surface of the flat plate collector to the atmosphere, a low emittance coating material for glazing should be selected, which reduces the heat loss. His discussion also gave the importance of using a selective absorber coating, when compared to the nonselective absorber coating, for a better performance, selective coating is more preferable since the required properties can be defined. Kaushika and Arulanantham [3] investigated the $\tau \alpha$ product of solar glazing. And he developed a method to determine the $\tau \alpha$ product for solar radiation using individual transmittance of cellular array and encapsulating cover. The developed method coincided with the value, calculated by theoretical. Gombert et al. [4] worked with the ways to 
increase the transmittance of the glass cover. When the performance of the collector was tested with an increased transmittance glass cover, it was found that the performance was increased. And he found that a transmittance of 3\% can be achieved in a glass with a porous sol-gel coating layer. Maatouk [5] reported the effect of the thickness of glass cover at low and high temperature, and the radiative and conductive heat transfer for one and two glasses. It was found that with the increase in thickness the heat flux through the glass decreases, at high temperature. And at low temperature of the absorber, the steady heat flux through the single glass cover is higher that obtained with doubleglazing. At high temperature of the absorber, the doubleglazing is more suitable rather than single glass. At high temperature of the absorber the emissive power emitting from the black absorber is too high. Therefore, the doubleglazing prevents better the heat loss from the absorber to the surroundings than the single glass cover. Khoukhi and Maruyama [6] calculated the instantaneous efficiency of solar collector in steady state by dividing the energy that reaches the absorber by the radiative heat flux at the outside surface of the glass cover and compared with the classical approach in which the top loss coefficient $U_{t}$ is assumed to be a linear function of the temperature difference between the plate and the surroundings. It was concluded from their work that in order to achieve a good performance, a rigorous radiative model should be applied for the glass cover and its properties. They also highlighted that effect of wind speed on the glass cover mean temperature is very important. Bhatt et al. [7] experimentally investigated the effect of wind speed, in the performance of solar flat plate collector with single glass cover. It was found that due to increase in wind speed the performance decrease and heat loss increases in the form of radiative loss. Akhtar and Mullick [8] studied the effect of absorption of solar radiation in glass cover. His work was done for single and doubled glazed flat plate collector, by considering the absorption of solar radiation in the glass cover and without considering the absorption of solar radiation in glass cover, and clearly explained their effect. The result showed that, due to the absorption of solar radiation in the glass cover the temperature of the glass increases which increase the radiative and convective heat loss, which reduce the performance of flat plate collector. Madhukeshwara and Prakash [9] investigated the performance of solar flat plate collector experimentally with different selective coatings for the location Davangere. With the help of selective coating it is possible to increase the incident radiation and heat resistance of the material which would increase the operating temperature. The result showed that among the three different selective coatings tested; the thermal efficiency for black chrome coating is higher. For the black chrome coating the absorptivity was 0.93 and its emissivity was 0.10 . From the literature it clear that there is absence of research work on finding the optimum number of transparent covers and effective refractive index which would increase the performance of solar flat plate collector. Most of the work has been carried out in the glass cover material property. Thus this paper focuses on finding the optimum number of transparent cover and its refractive index, which would correspondingly increase
TABLE 1: Specification of flat plate collector.

\begin{tabular}{|c|c|}
\hline Description & Specification \\
\hline $\begin{array}{l}\text { Collector dimension (Length } \\
\times \text { Width) }\end{array}$ & $1.6 \mathrm{~m} \times 1.1 \mathrm{~m}$ \\
\hline Collector type & Flat plate \\
\hline $\begin{array}{l}\text { Absorber dimension (Length } \\
\times \text { Width) }\end{array}$ & $1.5 \mathrm{~m} \times 1.0 \mathrm{~m}$ \\
\hline Plate to cover spacing & $2.5 \mathrm{~cm}$ \\
\hline Spacing between covers & $2.5 \mathrm{~cm}$ \\
\hline Thermal conductivity of plate & $35 \mathrm{~W} / \mathrm{m}-{ }^{\circ} \mathrm{C}$ \\
\hline Plate thickness & $2 \mathrm{~mm}$ \\
\hline Cover thickness & $2 \mathrm{~mm}$ \\
\hline Plate absorptivity/emissivity & 0.95 \\
\hline Outer diameter of lateral tube & $18 \mathrm{~mm}$ \\
\hline Inner diameter of lateral tube & $14 \mathrm{~mm}$ \\
\hline Tube center to center distance & $12 \mathrm{~cm}$ \\
\hline $\begin{array}{l}\text { Glass cover } \\
\text { absorptivity/emissivity }\end{array}$ & 0.88 \\
\hline $\mathrm{K} \delta_{C}$ & 0.0524 per plate \\
\hline Adhesive resistance & Negligible \\
\hline $\begin{array}{l}\text { Fluid to tube heat transfer } \\
\text { coefficient }\end{array}$ & $205 \mathrm{~W} / \mathrm{m}^{2}-{ }^{\circ} \mathrm{C}$ \\
\hline Water flow rate & $70 \mathrm{~kg} / \mathrm{hr}$ \\
\hline Inlet water temperature & $60^{\circ} \mathrm{C}$ \\
\hline Ambient temperature & $25^{\circ} \mathrm{C}$ \\
\hline Wind speed & $3.1 \mathrm{~m} / \mathrm{s}$ \\
\hline Back insulation thickness & $5 \mathrm{~cm}$ \\
\hline $\begin{array}{l}\text { Insulation thermal } \\
\text { conductivity }\end{array}$ & $0.04 \mathrm{~W} / \mathrm{m}-{ }^{\circ} \mathrm{C}$ \\
\hline Side loss coefficient & 10 percent of bottom loss \\
\hline Collector tilt & Latitude (12.916) \\
\hline Surface Azimuth angle & $0^{\circ}$ \\
\hline Date & January 21st \\
\hline For January 21st $A, B, C$ value & $610 \mathrm{~W} / \mathrm{m}^{2}, 0.00,0.242$ \\
\hline Location of flat plate collector & VIT University $\left(12.96^{\circ} \mathrm{N}, 79.15^{\circ} \mathrm{E}\right)$ \\
\hline
\end{tabular}

the performance of solar flat plate collector. The theoretical investigation is done in VIT University.

\section{Materials and Methods}

Thermal and optical efficiency of solar flat plate collector is calculated without cover, 1 cover, 2 covers, and 3 covers. In each cover the efficiency is calculated with the effect of refractive index 1.1, 1.2, 1.3, 1.4, 1.5, 1.6, and 1.7. Altogether about 21 different cases are calculated for a single day January 21st from morning $6 \mathrm{am}$ to evening $6 \mathrm{pm}$, at an interval of every half an hour. The specification and dimension of the solar flat plate collector that are considered to calculate the performance of the liquid flat plate collector are given in Figure 1 and Table 1. 
The first step in the numerical calculation [10] is to find the declination for day number using the below formula, the day number indicates the day of the year from day 1 to day 365 , to the corresponding date. Consider

$$
\text { Declination } \delta=23.45 \sin \left\{\frac{360(284+n)}{365}\right\} \text {. }
$$

Now

$$
\begin{aligned}
& \text { Equation of time (EOT) } \\
& \qquad=9.87 \sin 2 B-7.53 \cos B-1.5 \sin B,
\end{aligned}
$$

where $B=360(n-81) / 364$. Consider

$$
\text { Solar time }=\text { watch time }-4\left(L_{\mathrm{st}}-L_{l o}\right)+\text { EOT } .
$$

The next step is to calculate the hour angle, using the solar time, and the hour angle with negative symbol indicates forenoon, and the hour angle with positive symbol indicates afternoon. Consider

$$
\text { Hour angle } \omega=15 \text { (solar time }-12) \text {. }
$$

The important value to be determined now is the zenith angle $\left(\theta_{z}\right)$ and incident angle $(\theta)$ using the formula

Zenith angle $\theta_{z}=\cos ^{-1}(\sin \emptyset \cdot \sin \delta+\cos \emptyset \cdot \cos \delta \cdot \cos \omega)$,

where zenith angle is the angle made by the sun's rays with the normal to the horizontal surface. Consider

Inciden angle $\theta$

$$
=\cos ^{-1}(\sin \delta \cdot \sin (\emptyset-\beta)+\cos \delta \cdot \cos \omega \cdot \cos (\emptyset-\beta)) .
$$

Now beam radiation tilt factor $\left(r_{b}\right)$ is defined as the ratio of the beam radiation flux falling on a tilted surface to that falling on a horizontal surface, in the case of beam radiation

$$
r_{b}=\frac{\cos \theta}{\cos \theta_{z}}
$$

For diffused radiation the tilt factor $\left(r_{d}\right)$ it is the ratio of the diffused radiation flux falling on the tilted surface to that falling on a horizontal surface. Consider

$$
r_{d}=\frac{1+\cos \beta}{2}
$$

Next is the tilt factor for reflected radiation which is the given as

$$
r_{r}=\rho\left\{\frac{1-\cos \beta}{2}\right\}
$$

Now with the help of constant $A, B, C$, the beam, diffused radiation is calculated, which is used to calculate the total input supplied to the flat plate collector. Consider

$$
I_{b n}=C * A * \exp \left[\left(-\frac{B}{\cos \theta_{z}}\right)\right] .
$$

In the above formula $A, B, C[10]$ are constant whose values are determined on a monthly basis, these values change for every month depending on the season. Consider

$$
\begin{gathered}
I_{b}=I_{b n} * \cos \theta_{z} \\
I_{d}=C * I_{b n} .
\end{gathered}
$$

Now with the help of beam and diffused radiation obtained by the formula the solar flux incident on the top surface of the cover can be determined,

$$
I_{T}=I_{b} r_{b}+I_{d} r_{d}+\left(I_{b}+I_{d}\right) r_{r}
$$

The transmittance, reflectance, and absorption are functions of the incoming radiation, thickness, refractive index, and extinction coefficient of the material. For our calculation the cover material is glass, with different refractive indexes. From the solar flux available on the top surface of the transparent cover, depending upon the transmissivity of the cover, there is a reduction in the solar flux that reaches the plate surface. For transmissivity by reflection and absorption the transmissivity-absorptivity product for beam radiation is calculated by considering the solar incidence angle as the angle of incidence, which is substituted in Snell's law

$$
\frac{\sin \theta_{1}}{\sin \theta_{2}}=\frac{n_{2}}{n_{1}}
$$

Here for the beam radiation $\theta_{1}=\theta_{z}$, and $n_{2} / n_{1}$ represents the refractive index value, thus from the above equation $\theta_{2}$, can be found. Consider

$$
\begin{gathered}
\rho_{I}=\frac{\sin ^{2}\left(\theta_{2}-\theta_{1}\right)}{\sin ^{2}\left(\theta_{2}+\theta_{1}\right)} \\
\rho_{I I}=\frac{\tan ^{2}\left(\theta_{2}-\theta_{1}\right)}{\tan ^{2}\left(\theta_{2}+\theta_{1}\right)} .
\end{gathered}
$$

$\rho_{I}$ and $\rho_{I I}$ are the reflectivities of two components of polarization, using which the transmissivity is found

$$
\tau_{r}=\frac{1}{2}\left(\frac{1-\rho_{I}}{1+(2 M-1) \rho_{I}}+\frac{1-\rho_{I I}}{1+(2 M-1) \rho_{I I}}\right) .
$$

In the above transmissivity formula based on reflection and refraction, $M$ represents the number of covers, which is an important parameter for transmissivity. Consider

$$
\tau_{a}=e^{-K \delta_{c} / \cos \theta_{2}}
$$

The above equation is used to determine the transmissivity based on absorption, here $K$ indicates the extinction coefficient, which is a material property, and $\delta_{c}$ represents the thickness of transparent cover. The transmissivity of the cover system of a collector can be obtained with adequate accuracy by considering reflection-refraction and absorption separately and is given by the product form

$$
\tau=\tau_{a} \cdot \tau_{r}
$$




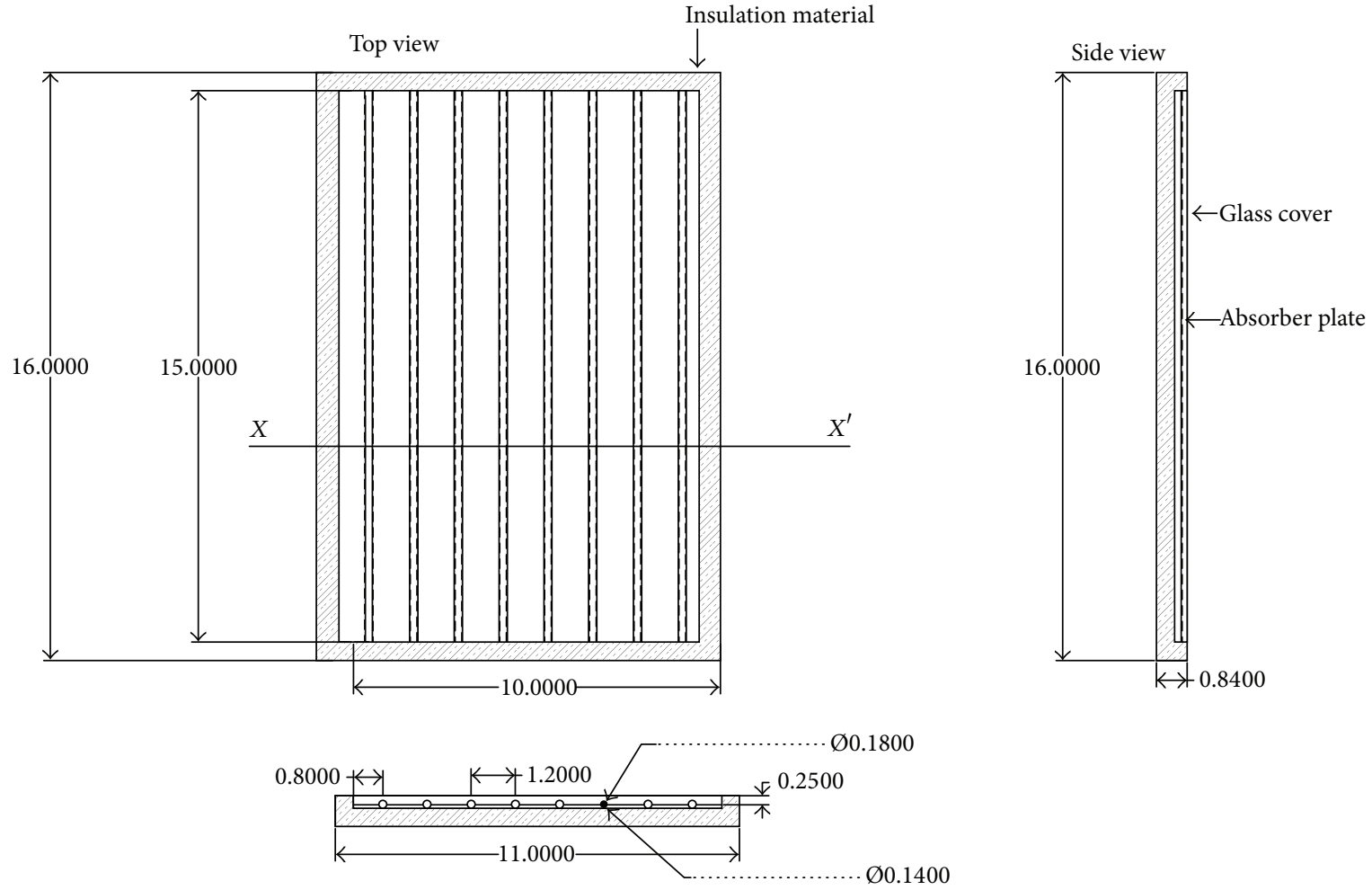

Cut section $X X^{\prime}$

All dimensions are in $\frac{1}{10} \mathrm{~m}$

FIGURE 1: Line diagram of flat plate solar water heater.

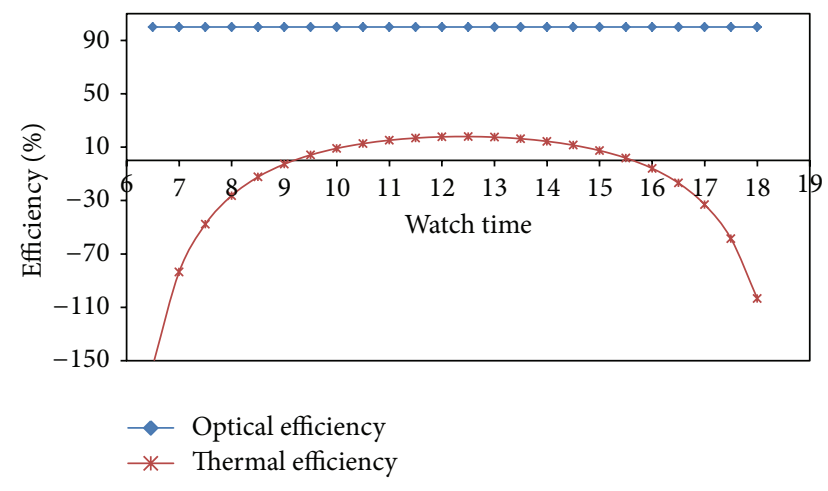

FIGURE 2: Efficiency versus watch time for without transparent cover.

Now the transmissivity-absorptivity product is to be calculated, which is defined as the ratio of the flux absorbed in the absorber plate to the flux incident on the cover, and it varies, respectively, for beam and diffused radiation,

$$
(\tau \alpha)_{b}=\frac{\tau \alpha}{1-(1-\alpha) \rho_{b}}
$$

Now similarly for diffused radiation $(\tau \alpha)_{d}$ is calculated and here as per the usual practice assumption, the diffuse radiation is equivalent to beam radiation coming at an angle of incidence of $60^{\circ}$.

Thus by substituting the value in the equation the solar radiation at absorber plate is calculated. The solar radiation absorbed by a collector area of absorber $S$ is equal to the difference between the incident solar radiation and the optical losses and is given by the expression

$$
S=I_{b} r_{b}(\tau \alpha)_{b}+\left\{I_{d} r_{d}+\left(I_{b}+I_{d}\right) r_{r}\right\}(\tau \alpha)_{d} .
$$

The optical efficiency of the solar flat collector is found by the considering the solar flux at the top surface of the glass cover as input and the solar flux that is received by the plate. Consider

$$
\text { Optical efficiency }=\frac{S}{I_{T}} .
$$

Now in order to find the collector heat removal factor and overall loss coefficient an iterative procedure is followed since both $F_{R}$ and $U_{l}$ cannot be directly determined and one value is independent on other. So the calculation for thermal efficiency of the flat plate collector is carried out by a reasonable assumption for overall heat loss coefficient. 


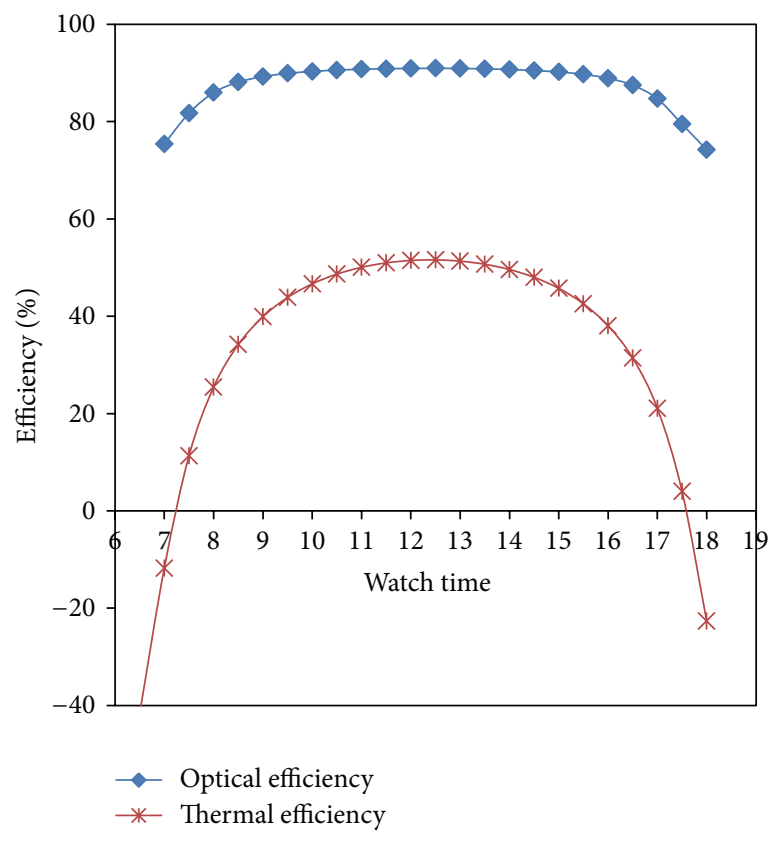

Figure 3: One cover, 1.1 refractive index.

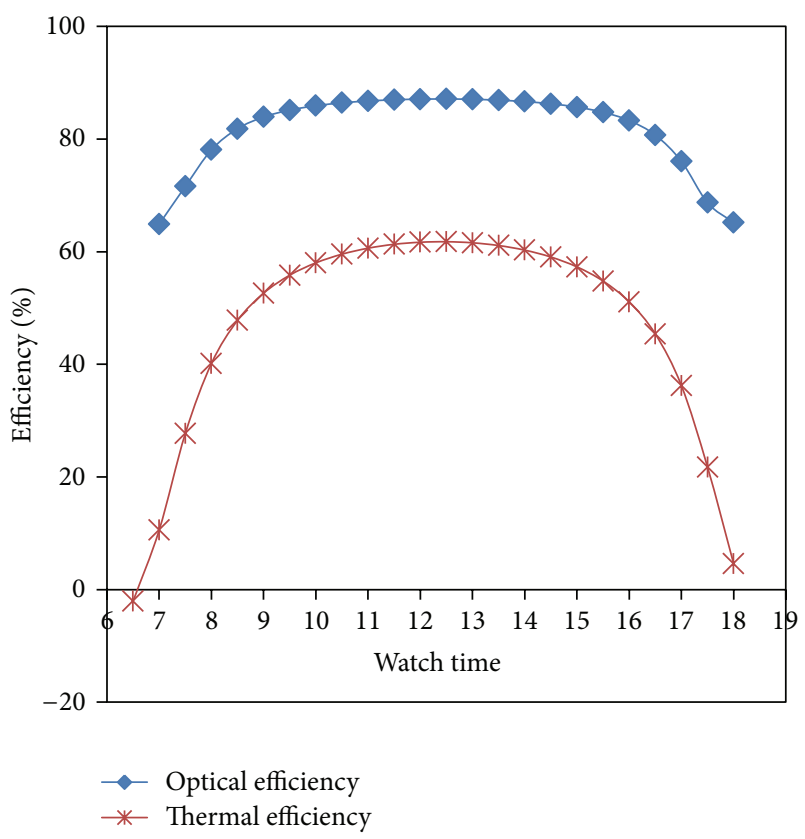

FIgURE 4: Two covers, 1.1 refractive index.

In order to find the collector heat removal factor $F_{R}$, collector efficiency factor $F^{\prime}$ is calculated using

$$
F^{\prime}=\frac{1}{W U_{l}\left[\frac{1}{U_{L}\left[\left(W-D_{0}\right) \emptyset+D_{0}\right]}+\frac{\delta_{a}}{k_{a} D_{0}}+\frac{1}{\pi D_{i} h_{f}}\right]},
$$

where $\emptyset=\tanh \left(m\left(W-D_{0}\right) / 2\right) /\left(m\left(W-D_{0}\right) / 2\right)$ is the effectiveness.

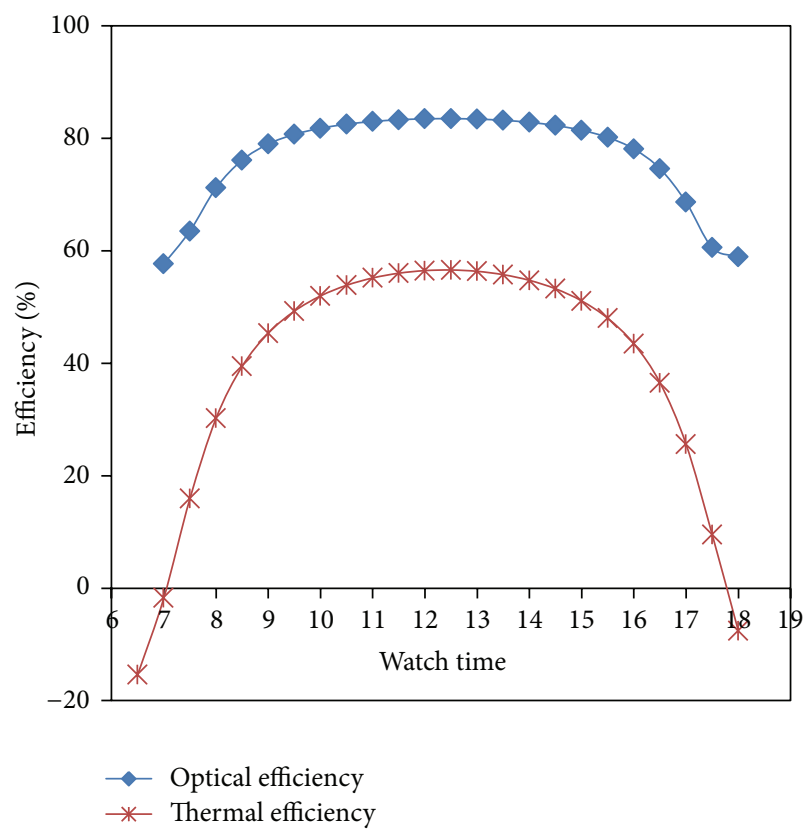

FIGURE 5: Three covers, 1.1 refractive index.

The term $F_{R}$ now can be calculated using the collector efficiency factor. Heat removal factor is an important parameter which denotes the thermal resistance that is encountered by the absorbed solar radiation in reaching the fluid. And the value of heat removal factor ranges from 0 to 1 . Consider

$$
F_{r}=\frac{m C_{p}}{\pi D_{o} U_{l} L}\left[1-\exp \left\{-\frac{F^{\prime}}{m C_{p} / \pi D_{o} U_{l} L}\right\}\right] .
$$




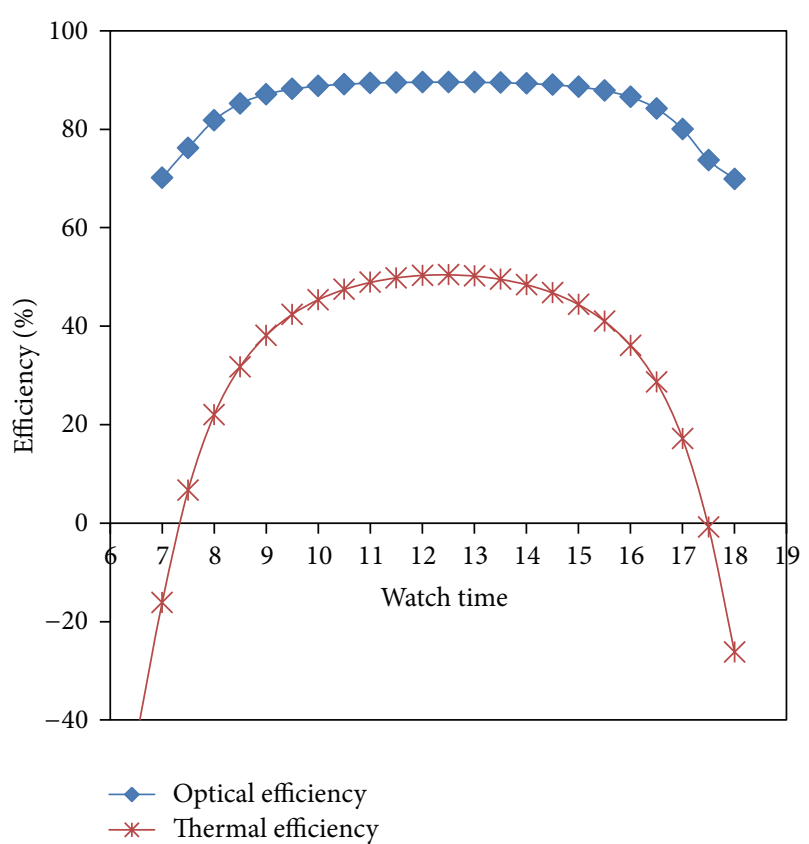

Figure 6: One cover, 1.2 refractive index.

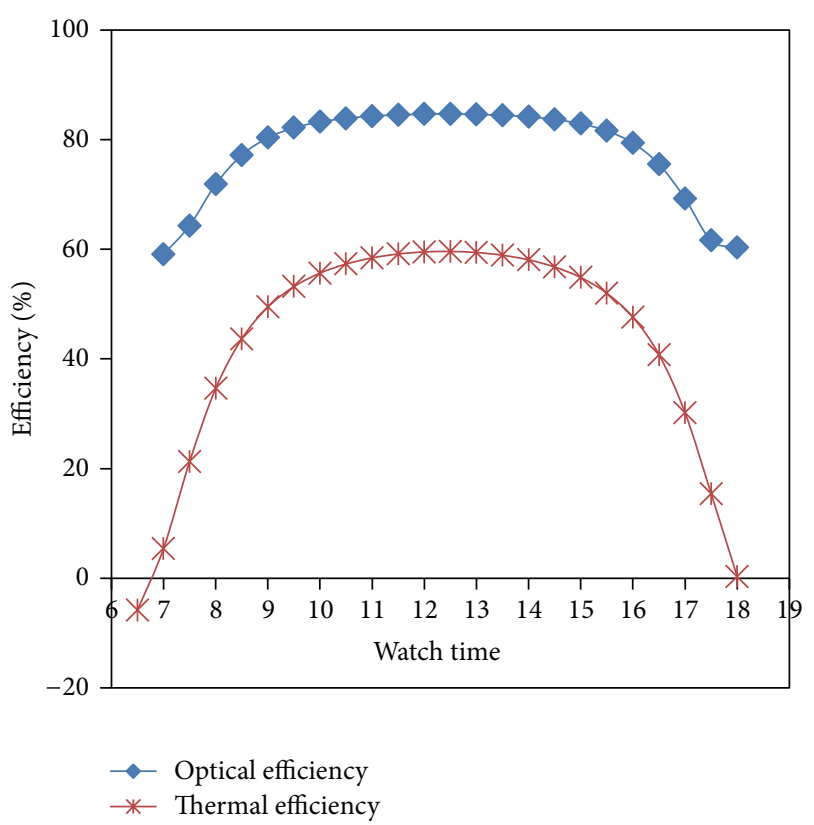

Figure 7: Two covers, 1.2 refractive index.

Now the total useful heat that is taken by the solar flat plate collector in heating the fluid can be calculated using

$$
q_{u}=F_{R}\left[S-U_{l}\left(T_{f i}-T_{a}\right)\right] .
$$

Now with the help of useful heat obtained, the heat loss can be determined which will be a base for calculating the absorber plate mean temperature of flat plate collector. Consider

$$
q_{l}=U_{l} A_{p}\left(T_{\mathrm{pm}}-T_{a}\right)
$$

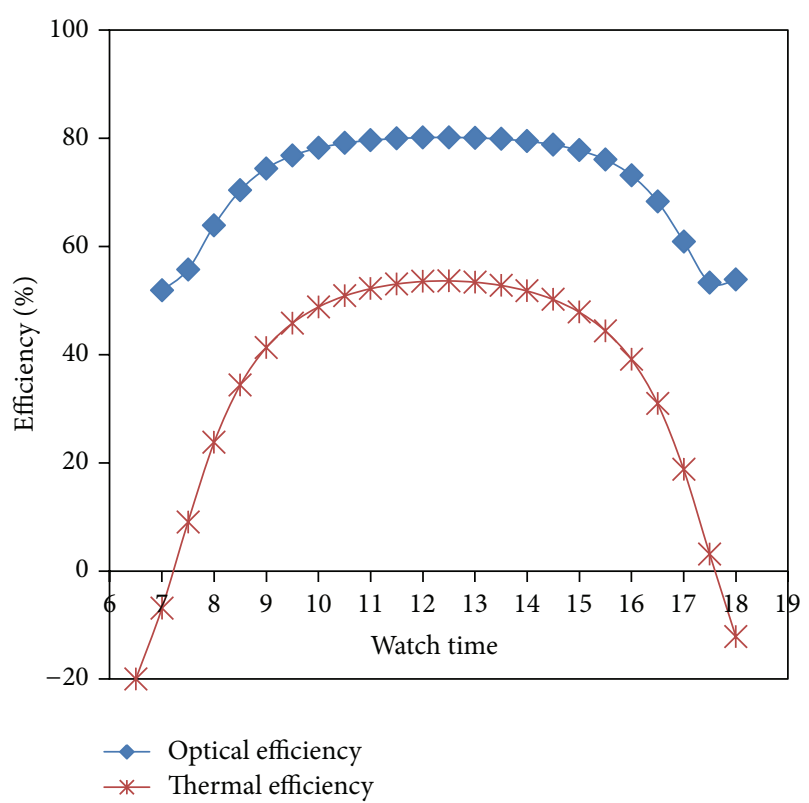

FIGURE 8: Three covers, 1.2 refractive index.

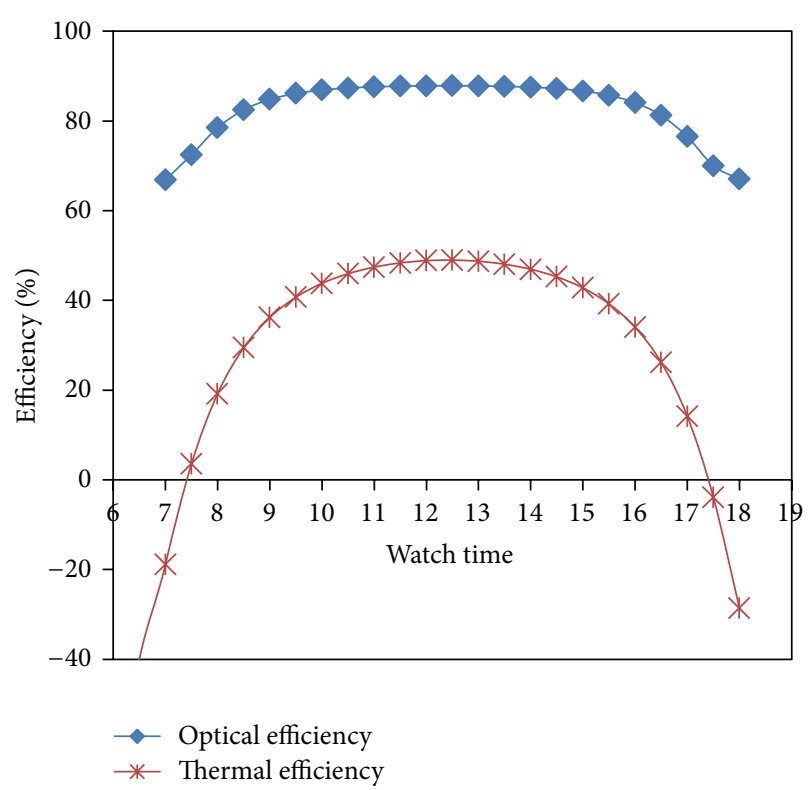

FIgURE 9: One cover, 1.3 refractive index.

here $q_{l}$ can be calculated from $\left(S \times A_{p}\right)-q_{u}$. Now the only unknown term is plate mean temperature which can be obtained by the above formula. After finding the plate mean temperature, the various losses, such as conduction, convection, and radiative loss comes into account, and by the top, bottom, and side heat loss the overall heat transfer coefficient assumed at the initialstep can be corrected. After finding the absorber mean temperature in order to calculated the top loss coefficient the temperature of the cover is to be assumed based on $T_{\mathrm{pm}}$ and $T_{a}$. At the top loss, convective and radiative losses are encountered, between the plate and cover, and even between the covers. Similarly, there is 
a radiative heat loss between the cover and the ambient which is influenced by the wind speed. Thus the combined equation for top loss is given as

$$
\frac{q_{t}}{A_{p}}=h_{p-c 1}\left(T_{\mathrm{pm}}-T_{c 1}\right)+\frac{\sigma\left(T_{\mathrm{pm}}^{4}-T_{c 1}^{4}\right)}{\left(1 / \varepsilon_{p}\right)+\left(1 / \varepsilon_{c 1}\right)-1} .
$$

In the above formula $h_{p-c 1}$ is calculated using nusselts number, where the value for air properties are taken from heat and mass transfer design data book, for the mean temperature $\left(T_{\mathrm{pm}}+T_{c 1}\right) / 2$.

Here

$$
\mathrm{Ra}_{L} \cos \beta=\frac{g\left(1 / T_{\mathrm{pm}}\right)\left(T_{\mathrm{pm}}-T_{c 1}\right) L^{3}}{\vartheta^{2}} \operatorname{Pr} \cos \beta
$$

depending on the above value, equation for nusselt number is taken

$$
\mathrm{Nu}_{L}=0.229\left(R a_{L} \cos \beta\right)^{0.252} .
$$

Now the convective heat transfer coefficient between the plate and cover can be determined using $h_{p-c 1}=\mathrm{Nu}_{L} * k / L$, where $L$ is the distance between the plate and cover. Now the loss between the cover to the top surface can be found using the below formula,

$$
\frac{q_{t}}{A_{p}}=h_{w}\left(T_{c 2}-T_{a}\right)+\sigma \varepsilon_{c}\left(T_{c 2}^{4}-T_{\text {sky }}^{4}\right),
$$

where $h_{w}$ is the convective heat transfer coefficient between the top most cover,

$\operatorname{Re}_{L}^{*}=$ wind speed $\times L^{*} / v$ where $L^{*}=4 A / P$, its the hydraulic diameter of the collector. Consider

$$
\begin{gathered}
j=0.86\left(\operatorname{Re}_{L}^{*}\right)^{-0.5} \\
h_{w}=j \rho C_{p}\left(3.1 \times 10^{3}\right) \operatorname{Pr}^{-2 / 3} .
\end{gathered}
$$

This is applicable when a single glass cover is used when two covers or more covers are used; once again the heat loss between those covers must also be calculated. And the all calculated heat loss value must be equal, which implies that the temperature of the cover assumed is correct. In the negative case, the process has to be iterated with different temperatures for the cover till an equal heat loss value for all the sections is obtained. Now with the heat loss the top loss coefficient can be calculated. Now the bottom heat loss is calculated by dividing the insulation thermal conductivity of the bottom material, with the back insulation thickness. As per the specification detail, the side loss is taken as 10 percent of the bottom heat loss coefficient. Thus adding $U_{t}$, $U_{b}, U_{s}$, the overall heat loss coefficient value can be obtained. The iterative procedure is continued till an accurate value of $U_{l}$ is achieved which is equal to the assumed overall heat loss coefficient. Now with the useful heat value the thermal efficiency of the solar flat plate collector is calculated as

$$
\text { Instantaneous efficiency }=\frac{q_{u}}{I_{T} \times A_{p}} .
$$

The above procedure and formula are used in every time value, to calculate the instantaneous efficiency of the solar flat plate collector with respect to different refractive indexes and different numbers of covers.

\section{Results}

When a solar flat plate collector is exposed to solar radiation, some of its radiation absorbs and the balance is reflected back. The conduction, convection, and radiation heat losses increase with increase in system temperature. In order to minimize these heat losses, glazing can be used with different types of material as transparent cover. The solar radiation is held back with transparent cover and a greenhouse effect is formed. The glazing has a property of being transparent to visible rays and being opaque to infrared rays. It results in an increase in inner temperature and also working fluid temperature. The refractive index is the property of transparent cover influences the optical efficiency and thermal efficiency of solar collecting system. Similarly the number of transparent covers also influences the above stated efficiency levels. In this regard, the current work is focused on development of optical efficiency and thermal efficiency variations with changes in both refractive index and number of transparent covers.

For January 21st, the performance of a flat plate solar water heater was calculated from morning $6 \mathrm{am}$ to evening $6 \mathrm{pm}$, at an interval of every half an hour. In the 1st case the performance of a flat plate collector was calculated without transparent cover. Figure 2 depicts the efficiency versus time curve for flat plate collector without transparent cover. Since, there is no cover the optical efficiency of the solar flat plate collector is $100 \%$. And the change in refractive index does not make any influence in the absence of transparent cover. From Figure 2 it is found at only from 9:40 am the flat plate collector produces hot water, and it is in the range of $4 \%$ to $17 \%$ at noon. This low efficiency of the flat plate collector is due to the conduction, convective, and radiative heat losses.

This is because the temperature always flows from a hot body to cold body, and maintains equilibrium, similarly the absorber plate losses heat in order to attain equilibrium with the atmosphere. The convective heat loss is mainly due to the wind at the top surface, whereas radiative loss is due to infrared rays. Thus the absorber plate temperature is low and simultaneously temperature of working system low.

The above graphs are plotted between watch time and their efficiency namely optical and instantaneous efficiency. Figures $3,6,9,12,15,18$ and 21 shows the efficiency versus time curve for refractive index 1.1 to 1.7 simultaneously with number of transparent cover 1. Figures 4, 7, 10, 13, 16, 19 and 22 shows the efficiency versus time curve for refractive index 1.1 to 1.7 simultaneously with number of transparent covers 2 . Figures 5, 8, 11, 14, 17, 20 and 23 shows the efficiency versus time curve for refractive index 1.1 to 1.7 simultaneously with number of transparent covers 3 . It is noted that for same watch time, with same number of cover, and different refractive index the collector with low refractive index show higher thermal efficiency. Similarly optical efficiency is high with low refractive index, and vice versa. Refractive index [11] is 


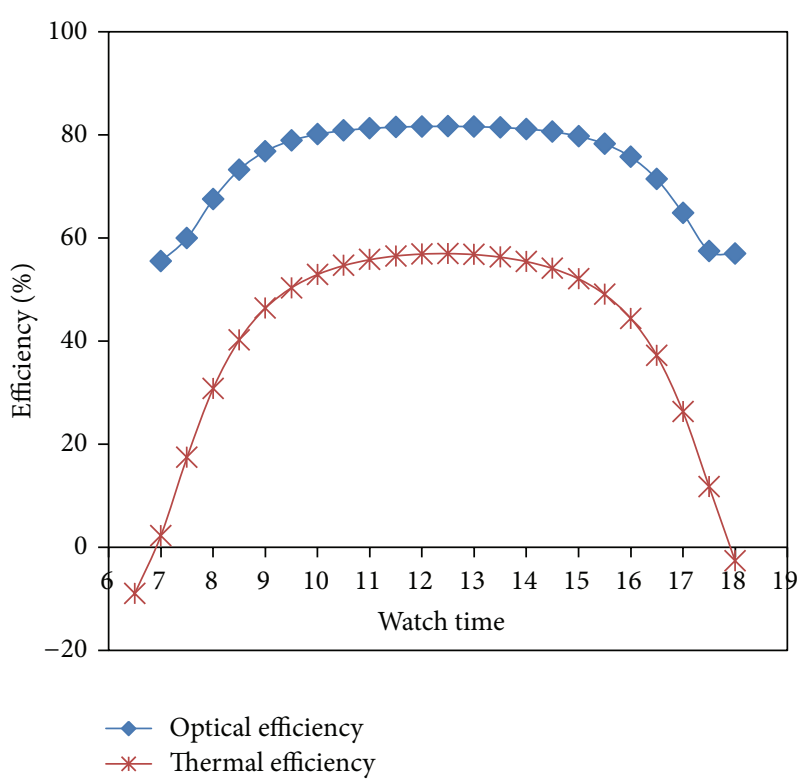

Figure 10: Two covers, 1.3 refractive index.

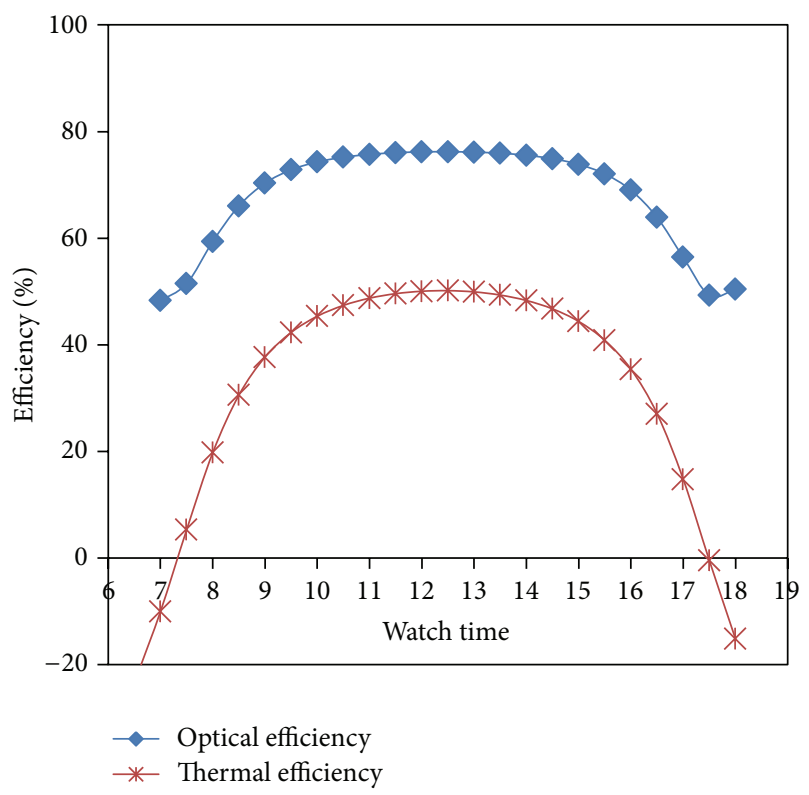

FIGURE 11: Three cover, 1.3 refractive index.

a function of speed of the light in the vacuum to speed of light in the substance and the speed of light in the substance is a function of frequency and wavelength,

$$
\begin{gathered}
n=\frac{c}{v}, \\
v=f \times \lambda, \\
n=\frac{c}{f \lambda} .
\end{gathered}
$$

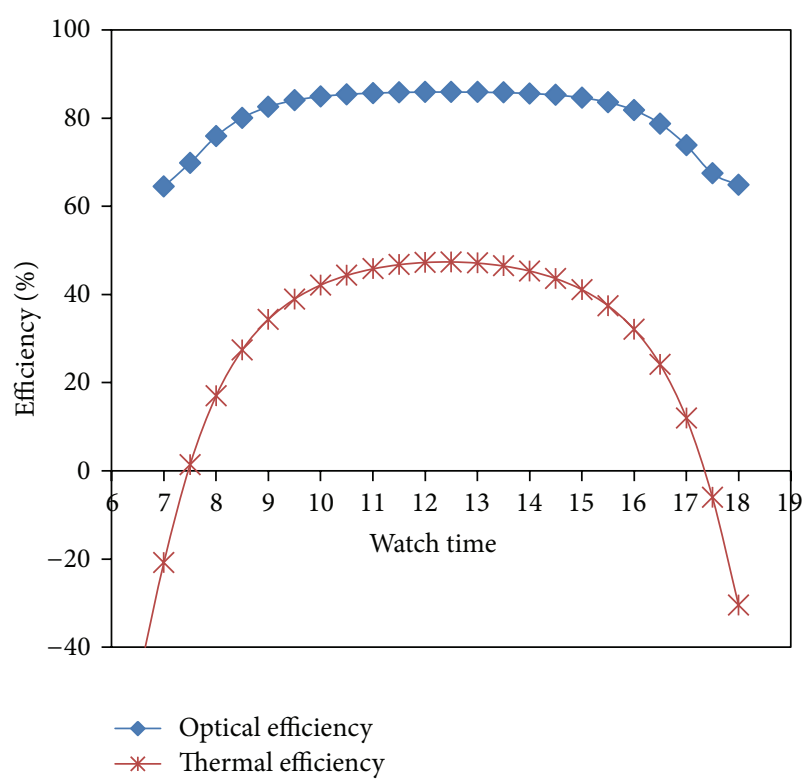

FIgURE 12: One cover, 1.4 refractive index.

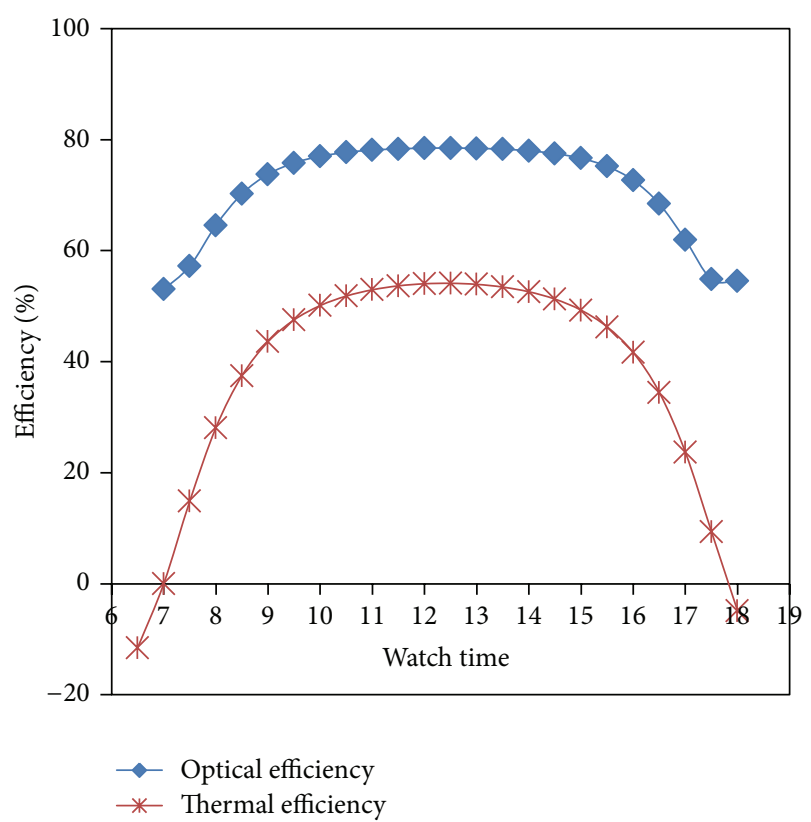

FIGURE 13: Two covers, 1.4 refractive index.

And from the above equation it clearly indicates that with increase in refractive index the wavelength of the rays decrease, thus the rays change from visible range to infrared range to which the glass acts as opaque, thus the transmittance of radiation becomes a consequence, which results in transmission of low solar radiation.

Figures 3, 4, and 5 show the performance of solar flat plate collector with refractive index 1.1 and different covers, 1,2 , and 3. In this case the solar flat plate collector with 1 cover at watch time of 12 noon gives an instantaneous efficiency of $51.47 \%$, with 2 covers, instantaneous efficiency of $61.68 \%$, and with 3 covers the instantaneous efficiency 


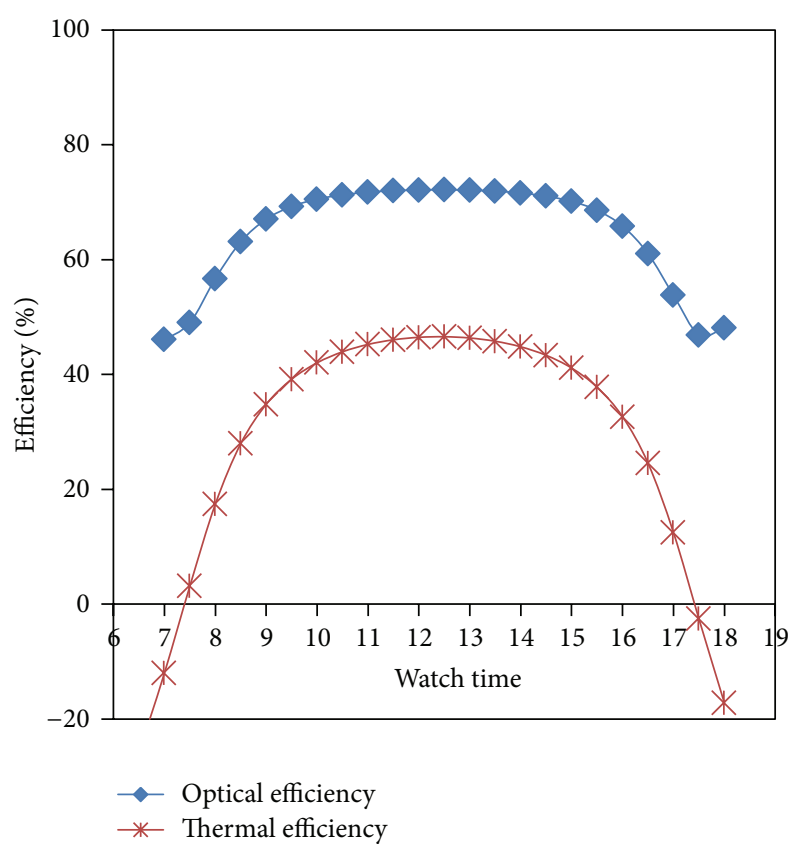

FIgURE 14: Three covers, 1.4 refractive index.

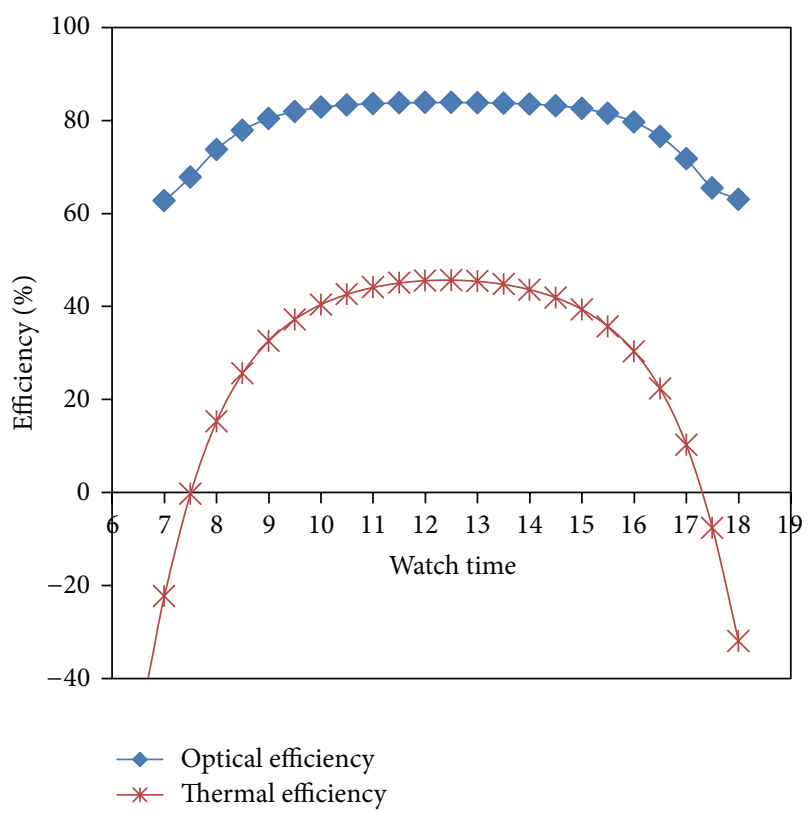

FIGURE 15: One cover, 1.5 refractive index.

of $56.46 \%$. The optical efficiency of the flat plate collector increases with increase in number of covers till an optimum number of transparent covers and decreases when it crosses the optimum value. It is because, when the rays pass through a separating medium a part of the radiation $(r)$ is reflected back at the upper surface of the cover and $(1-r)$ amount of radiation reaches the lower surface of the cover. Now due to refraction $(1-r) r$ radiation is reflected and $(1-r)^{2}$ of radiation reaches the next cover. The same process is reversed when the rays tend to leave the cover. This absorption,

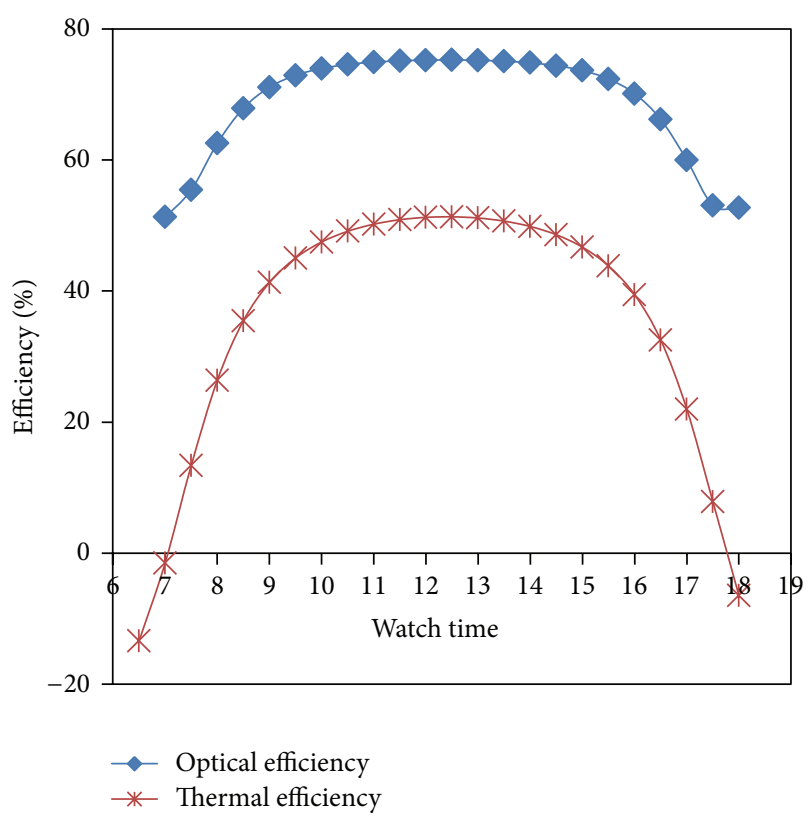

FIGURE 16: Two covers, 1.5 refractive index.

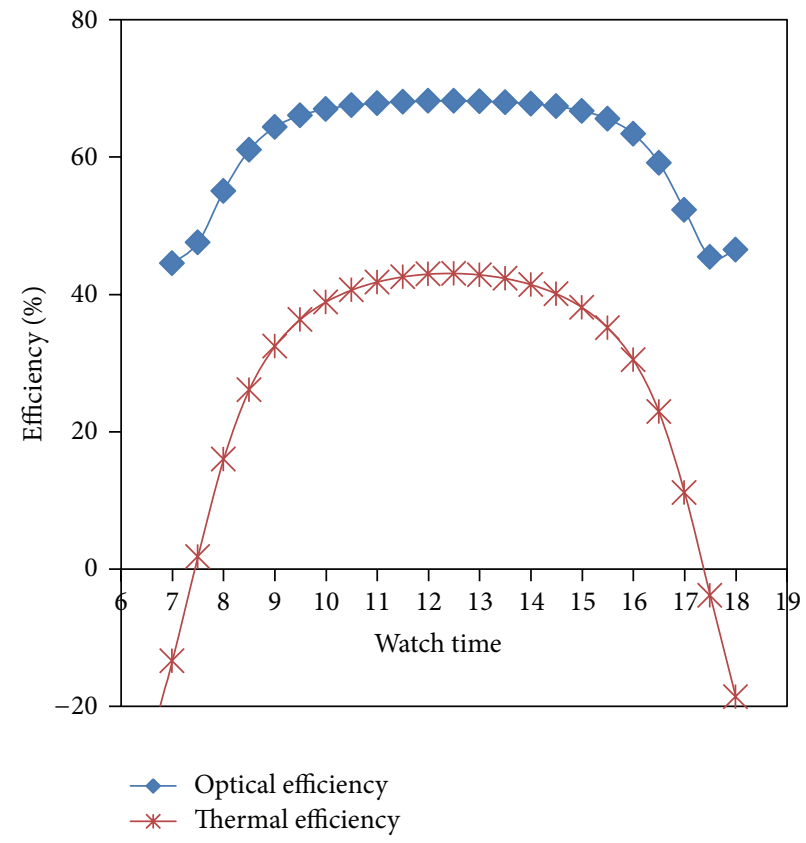

FIGURE 17: Three covers, 1.5 refractive index.

reflection, and transmissivity of the solar radiation through the transparent cover reduces the transmissivity-absorptivity $(\tau \alpha)$ product. There is corresponding reduction in $(\tau \alpha)_{b}$ and $(\tau \alpha)_{d}$ respective to the beam and diffused radiation. The lower value of $(\tau \alpha)$ decreases the flux $S$ absorbed in the absorber plate. Due to this reason performance of the solar flat collector increases with increase in number of transparent cover till an optimum value. After the optimum number of covers the resistance to transmit the solar radiation to the flat plate increases with increase in number of covers, thus 


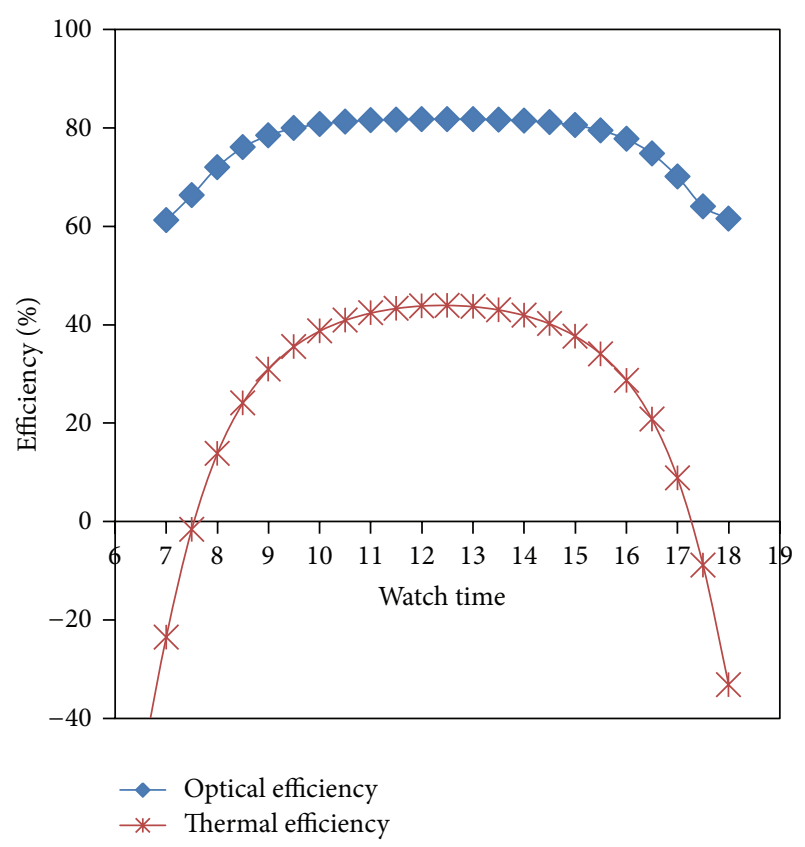

FIGURE 18: One cover, 1.6 refractive index.

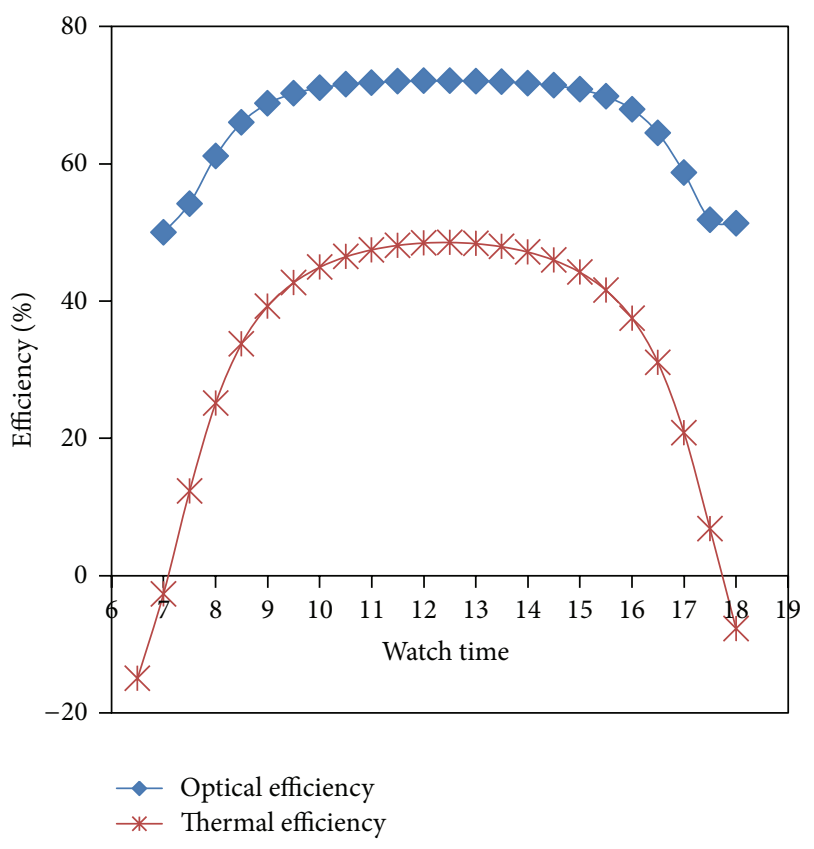

Figure 19: Two covers, 1.6 refractive index.

the performance of the liquid flat plate collector decreases in the latter case.

\section{Conclusion}

In this work the effect of number of transparent covers and the refractive index of the transparent cover are theoretically investigated. The work is focused on the suitable number of covers with appropriate refractive index to achieve a high

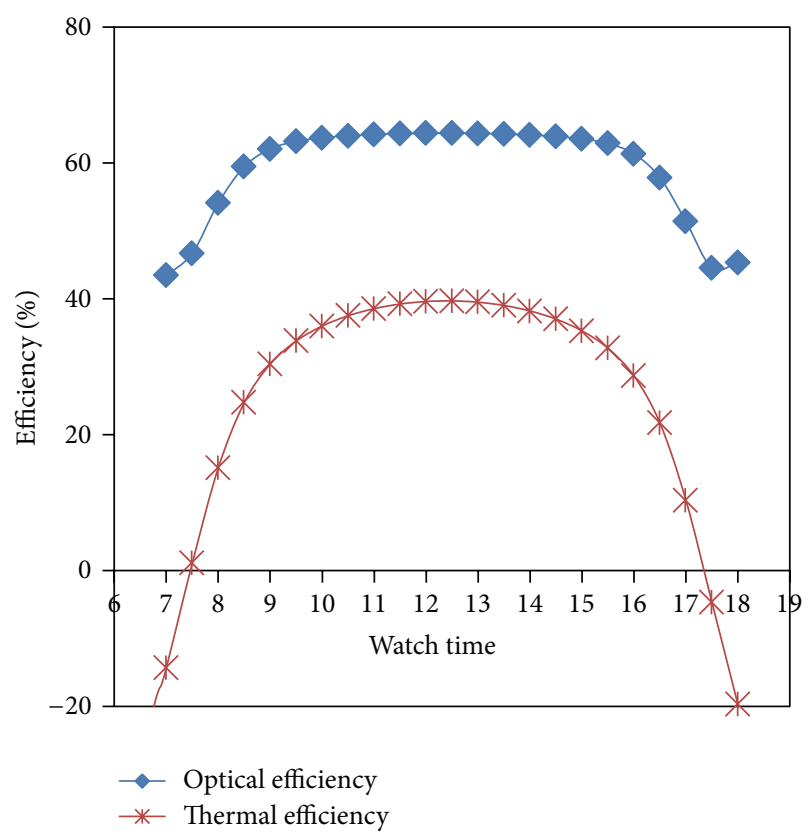

Figure 20: Three covers, 1.6 refractive index.

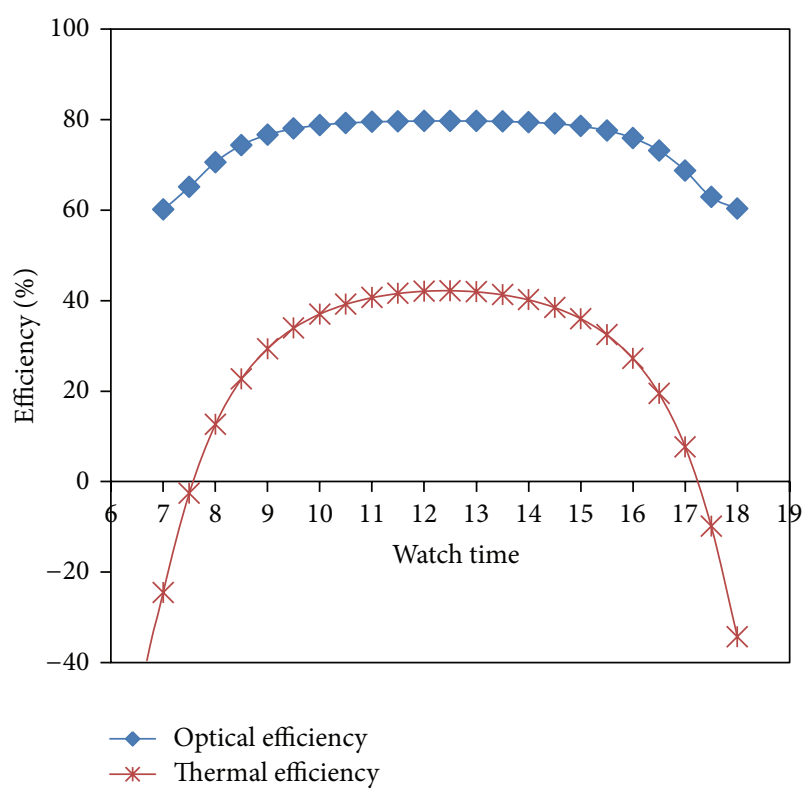

FIgURE 21: One cover, 1.7 refractive index.

value of instantaneous efficiency for solar flat plate water heater. The theoretical calculations were done for one, two, and three numbers of covers with refractive index from 1.1 to 1.7. Within the range of zero to three numbers of transparent numbers of cover the optimum number of cover to give better performance is found, thus this range is selected. It was found that the solar flat plate collector with two transparent covers with 1.1 refractive index resulted a maximum efficiency when compared to other combination of number of transparent covers and refractive indices. 


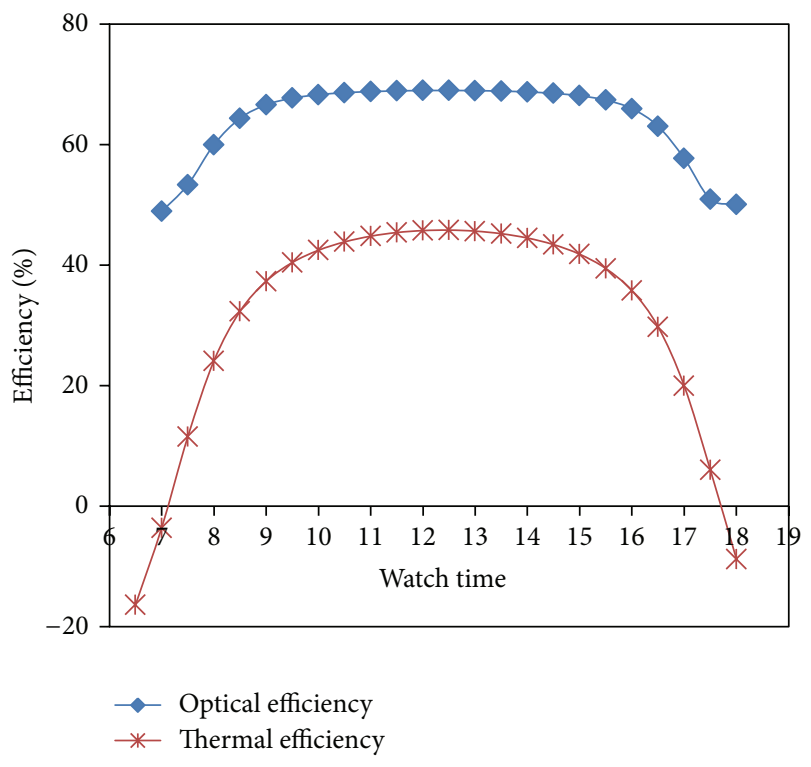

FIGURE 22: Two covers, 1.7 refractive index.

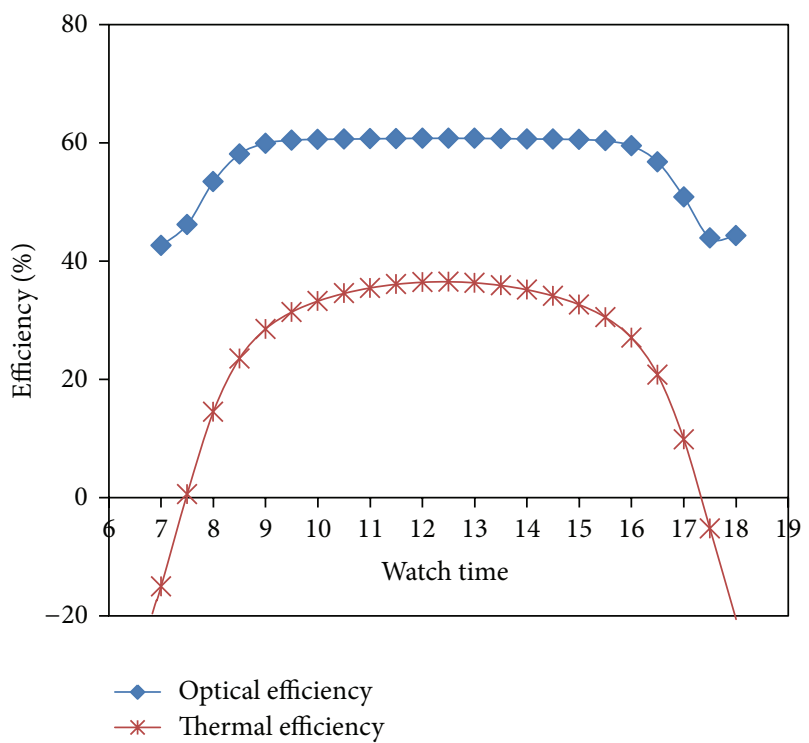

FIgURE 23: Three covers, 1.7 refractive index.

\section{Conflict of Interests}

The authors declare that there is no conflict of interests regarding the publication of this paper.

\section{References}

[1] "Horace de Saussure U.S. Department of Energy-Energy Efficiency and Renewable Energy," "The History of Solar", https://wwwl.eere.energy.gov/solar/pdfs/solar_timeline.pdf.

[2] C. M. Lampert, "Advanced optical materials for energy efficiency and solar conversion," Solar and Wind Technology, vol. 4, no. 3, pp. 347-379, 1987.
[3] N. D. Kaushika and M. Arulanantham, "Transmittanceabsorptance product of solar glazing with transparent insulation materials," Solar Energy Materials and Solar Cells, vol. 44, no. 4, pp. 383-395, 1996.

[4] A. Gombert, W. Glaubitt, K. Rose et al., "Glazing with very high solar transmittance," Solar Energy, vol. 62, no. 3, pp. 177-188, 1998.

[5] K. Maatouk, "Non-gray radiative and conductive heat transfer in single and double glazing solar collector glass covers," International Journal of Thermal Sciences, vol. 45, no. 6, pp. 579$585,2006$.

[6] M. Khoukhi and S. Maruyama, "Theoretical approach of a flatplate solar collector taking into account the absorption and emission within glass cover layer," Solar Energy, vol. 80, no. 7, pp. 787-794, 2006.

[7] M. Bhatt, S. K, and S. NChanniwala, Distribution of Heat Losses in a Single Glazed Flat Plate Collector at Variable Wind velocity An Experimental Simulation, vol. 5, World Academy of Science, Engineering and Technology, 2011.

[8] N. Akhtar and S. C. Mullick, "Effect of absorption of solar radiation in glass-cover(s) on heat transfer coefficients in upward heat flow in single and double glazed flat-plate collectors," International Journal of Heat and Mass Transfer, vol. 55, no. 1-3, pp. 125-132, 2012.

[9] N. Madhukeshwara and E. S. Prakash, "An investigation on the performance characteristics of solar flat plate collector with different selective surface coatings," International Journal of Energy and Environment, vol. 3, no. 1, pp. 99-108, 2012.

[10] S. P. Sukhatme, Solar Energy Principles of Thermal Collection and Storage, Tata McGraw-Hill, New York, NY, USA, 2nd edition, 1984.

[11] A. Abadi, "Optical properties," in Material Properties, chapter 8, http://www.uotechnology.edu.iq/appsciences/filesPDF/ material/lectures/2c/3-Materials_prperties8.pdf. 


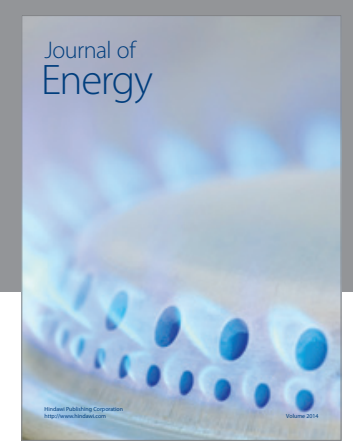

Journal of

Industrial Engineering
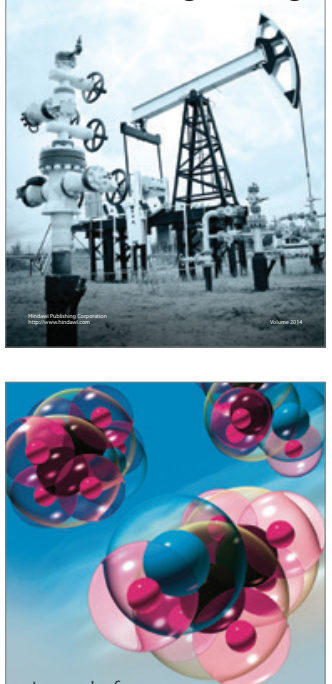

Fuels
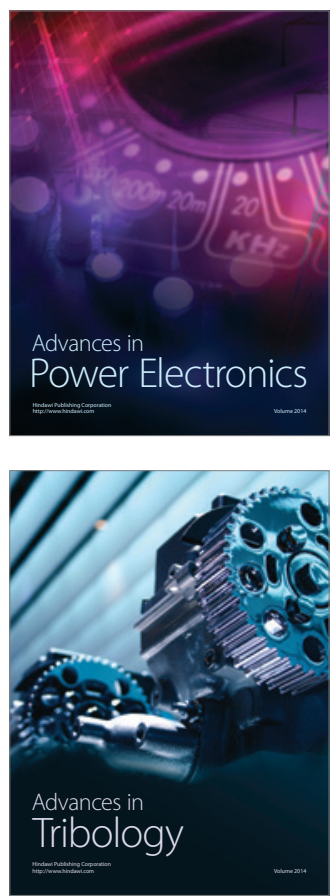

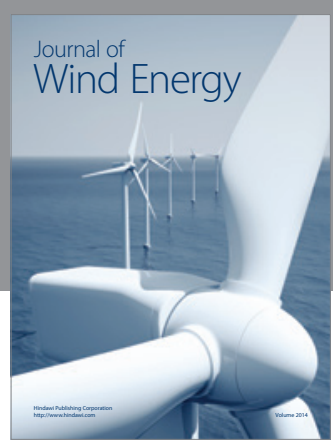

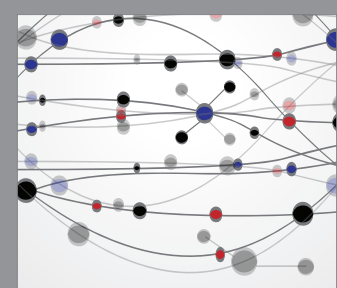

The Scientific World Journal

Submit your manuscripts at http://www.hindawi.com

Journal of

Structures
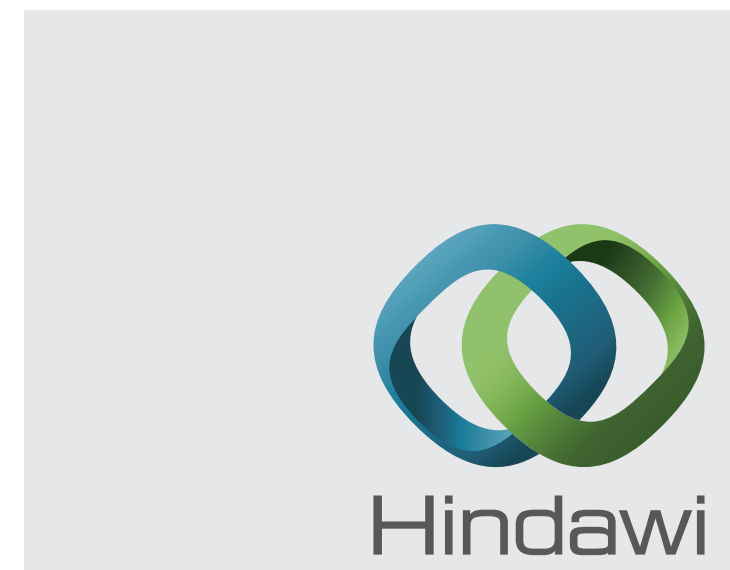

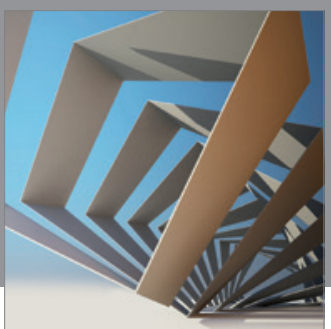

Rotating

Machinery
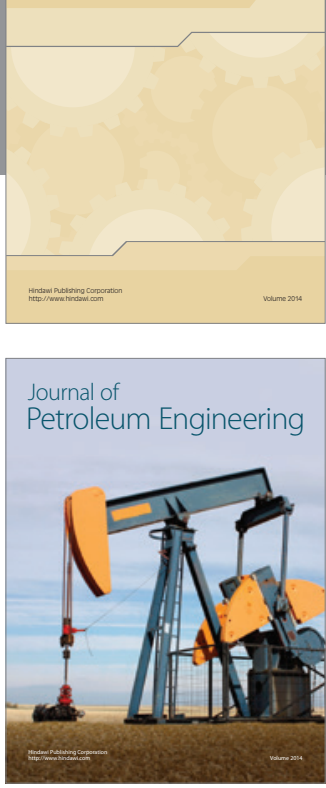

Journal of

Solar Energy
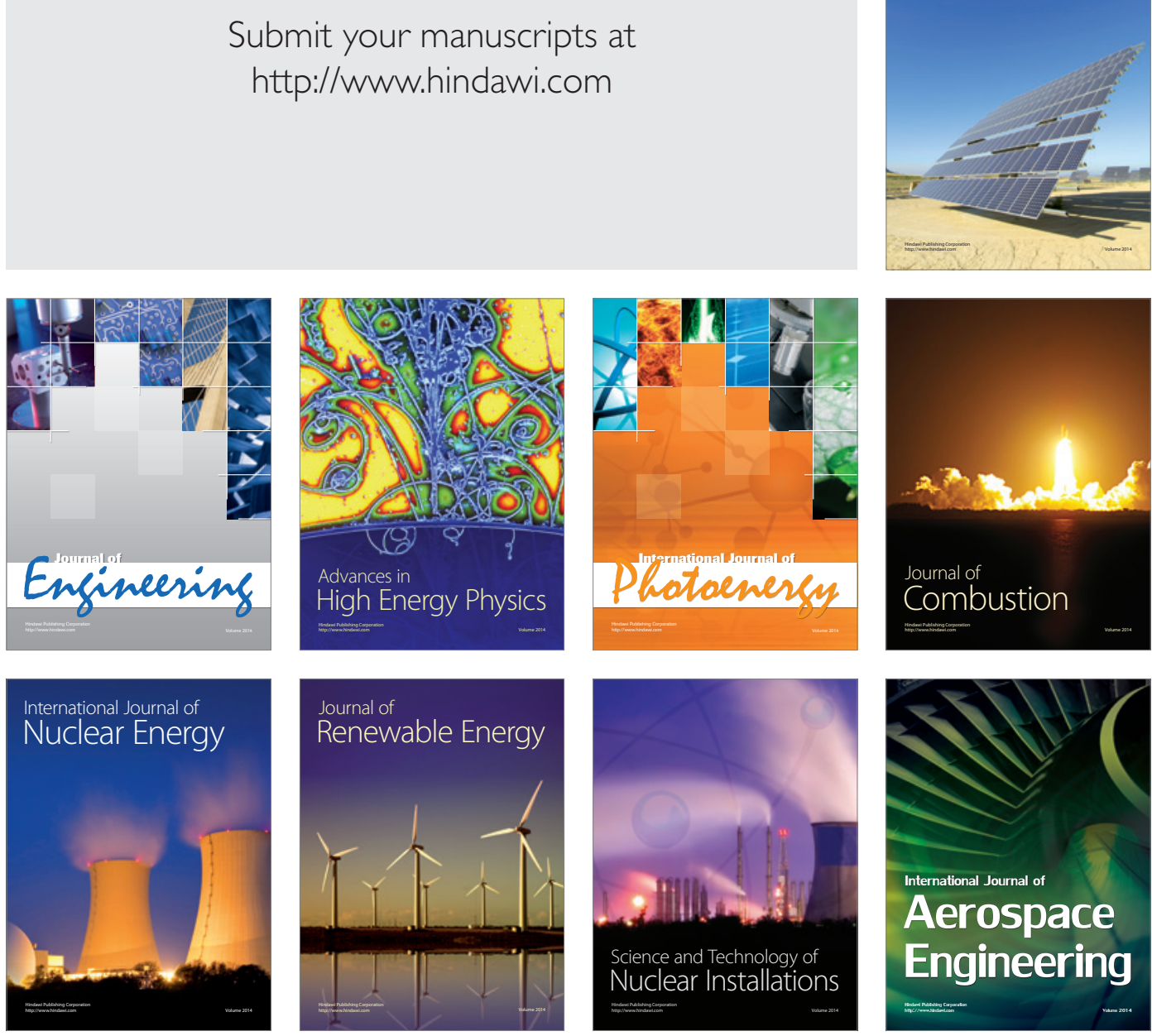